\title{
O ESCRAVO NEGRO NOS CÁRCERES DE PORTO ALEGRE: SUGESTÕES DE UMA DOCUMENTAÇÃo Do SeCULO XIX
}

\author{
Margaret Marchiori Bakos
}

\section{INTRODUÇÃO}

Há poucos estudos sobre a História Social do negro no Rio Grande do Sul. As pesquisas realizadas no assunto apenas referenciam o tratamento recebido pelo escravo nas fazendas de criação, charqueadas e centros urbanos. As fontes tradicionais de tais trabalhos são em geral os depoimentos de viajantes estrangeiros do século XIX, como as obras clássicas de Dreys e Saint Hillaire1.

Entre as pesquiisas novas, com outras fontes, cita-se o trabalho de Raphael Copstein - "Subsídio do estudo da escravatura no sul do Estado". Copstein analisa documentos do registro de recolhimento de escravos à cadeia da cidade de Rio Grande, entre 1857 e 18592. A partir do estudo infere uma série de dados sobre a situação social do negro rio-grandense.

A idéia do presente trabalho relaciona-se com à descoberta de documentação sobre prisões em Porto Alegre, no século passado.

Trata-se de relatórios de comissões nomeadas para inspecionar as condições de sobrevivência dos indivíduos encerrados nas prisões porto-alegrenses. Entre os elementos mais importantes para a análise social do período salienta-se o encarceramento de pessoas de cor branca e criminosas juntamente com elementos de cor preta e inocentes. A explicação do fato, segundo se depreende, pela documentação, é o rigorismo do tratamento reservado ao escravo negro.

É necessário referenciar a dificuldade para localizar documentos sobre as prisões de Porto Alegre.

Através de um mapa da cidade tem-se indicações de um prédio, onde se dizia que funcionava simultaneamente o Palácio da Presidência, Câmara e Presídio. 
Dificulta ainda a pesquisa o uso indiscriminado, nos documentos, dos termos Prisão, Cárcere, Cadeia Judicial, Cadeia Pública e Presiganga. A falta de especificações das instituições permite certa confusão sobre as funções de cada uma delas. Fato que pode ser esclarecido com futuras pesquisas.

A acadêmica de História - Eliane Silveira - deve-se o levantamento de fontes primárias importantes para o trabalho.

\section{2 - A CADEIA PÚBLICA DE PORTO ALEGRE - EM 1824 - NAS PALAVRAS DO PRESIDENTE DA PROVINNCIA}

José Feliciano Fernandes Pinheiro, Visconde de São Leopoldo, Presidente da Província do Rio Grande do Sul, entre 18243 a janeiro de 1826, em um dos seus primeiros atos oficiais, visita a Cadeia Pública de Porto Alegre. Ele escreve a seguir ofício sobre o assunto endereçado ao Juiz de Fora, Presidente e Oficiais da Câmara.

O Presidente confessa-se horrorizado com "a estreitura ? abafo"4 da prisão. Diz Pinheiro que tais condições tornam u local propício para a infecção e a morte, em lugar de proporcionar abrigo e segurança para os infelizes, conforme reza a lei.

As condições da prisão contrariam as disposições expressas no § 21, Art. 179, Tít. 8 ?a Constituição do Império:

"As cadeias serão seguras, limpas e bem arejadas, havendo diversas casas para separação dos réus, conforme suas circunstâncias e natureza de seus crimes."5

O fato torna-se mais grave porque a prisão em questão pertence à cidade cabeça de comarca. Isto pressupõe que o presídio seja menos desleixado, mais amplo e com capacidade para receber delinqüentes de toda a Província, que esperam julgamento na Junta de Justiça.

O Presidente reconhece que a situação não se deve à negligência das autoridades, a quem toca privativamente a inspeção e economia de semelhantes ofícios. Os primeiros alicerces da nova cadeia - na quadra fronteira dos armazéns nacionais - na zona portuária - demonstram o interesse na construção do prédio. Entretanto há falta de verbas para dar continuidade a obra. Diante disso, Fernandes Pinheiro faz a 
doação - no Augusto Nome de Sua Magestade Imperial - à Câmara de Porto Alegre de

\begin{abstract}
"todos os terrenos, que se acharem sem Títulos legítmos de concessão, bordando a margem do Rio, no sítio com a denominação antiga de Arsenal, e partindo desde os morros conhecidos da mesma Câmara até a desembocadura $\mathrm{da}=$ Rua Formosa $=(\ldots)$ os quais terrenos, depois de convenientemente repartidos, sejão vendidos em Hasta Pública, e o seu produto aplicado para edificação da referida Cadeia, precedendo a Licença de Sua Magestade Imperial, que para tais alienações exige o Alvará de 2 de Dezembro de 1626."6
\end{abstract}

A iniciativa do Presidente não é levada adiante, conforme se constata a seguir.

3 - RELATÓRIO DA PRIMEIRA COMISSÃO ENCARREGADA PELA CÂMARA MUNICIPAL DE VISTORIA EM CARCERES E ESTABELECIMENTOS DE CARIDADE EM PORTO ALEGRE — OUTUBRO DE 1831 -

Em 3 de outubro de 1831, sendo Presidente da Província Manoel Antonio Galvão, nomeia-se Comissão para vistoriar as Prisões e estabelecimentos de Caridade de Porto Alegre. A atitude está conforme o Art. 36, Tít. I, da Lei de 1 ' de outubro de 1828, que cria Câmaras Municipais em cada cidade e vila do Império e determina:

"Em cada reunião, nomearão uma comissão de cidadãos, de cinco pelo menos, a quem encarregarão a visita das provisões civis, militares e eclesiásticas, dos cárceres; dos conventos regulares, e de todos os estabelecimentos públicos de caridade para informarem de seu sam..."7 $\mathrm{e}$ dos melhoramentos que preci-

A Comissão, de cinco elementos, envia relatório ao Presidente da Câmara, manifestando-se indignada com o estado em que se encontra a "A Cadeia de Justiça".

Segundo o relato, uma das peças da cadeia constitui-se de um quarto pequeno e imundo, onde jazem 68 homens. Os in- 
felizes sofrem vida tão penosa que "apenas se pode chamar de vida, porque os míseros que a vivem tem." 8

O mais grave da situação é que apenas 39 presos cumprem pena por crimes diversos. Os restantes 29 homens são escravos aprisionados pelo simples arbítrio de seus senhores e outros que "ali estão depositados pelo bárbaro e ilegal costume de depositar a misera inocência na habitação dos criminosos." 9

A Comissão pede a atenção da Câmara para a situação. Argumenta que a cadeia é lugar de criminosos e não casa de depósito e enfatiza o pensamento10: "... as prisões foram feitas para a correção do crime, e não para saciar o arbítrio, e a barbaridade dos senhores dos míseros escravos." 11

A este fato seguem-se outros abusos, que a Comissão aponta, como perniciosos:

"1 A falta de comodidade aos legalmente presos, o que vai de encontro a Constituição, e as luzes do século;

2 A inteira depravação dos costumes porque os escravos por sua ignorância sujeitos inteiramente a seus hábitos tendo contraído o de viverem com os criminosos, bebendo suas lições, quando dali saem estão aptos a combater todos os crimes;

3 A opressão da inocência porque o depositário geral envia para ali aqueles que são cometidos a sua guarda;"

O relatório ainda revela as atrocidades cometidas contra os escravos. Os infelizes recebem cerca de 200 açoites com um instrumento denominado de - ... - (ilegível), que valem por 1000 açoites, devido aos ferimentos que causa.

Sabe-se que tais crueldades são realizadas com a conivênc'a de autoridades. A Câmara Municipal recebe, através de seu procurador, pagamento em dinheiro por cada açoite aplicado.

A Comissão, ao mesmo tempo em que se desculpa pela agressividade com que relata os fatos, aponta os aconteci- 
mentos com os escravos como um detestável comércio com o sangue humano. Atribui o seu estado de espírito tão revoltado aos sons dos gemidos e aos urros de dor dos infelizes que ainda soam em seus ouvidos.

O relatório defende os castigos moderados e que visem a correção dos crimes, explicando que as barbaridades cometidas nas cadeias acarretam funestas conseqüências sociais. Os presos - criminosos ou não - habituam-se aos gemidos e às dores atrozes, infligidas sem compaixão, perdendo todo o senso de humanismo que possuem. É evidente que estes indivíduos, uma vez soltos, ao findar a sentença ou por "mercê do senhor", estão prontos para cometer com frieza toda a sorte de delitos.

Pelo exposto a Comissão encarece à Câmara toda a ação possível e imediata para remediar os males.

$\mathrm{Na}$ mesma cadeia, em quarto separado, mulheres são prisioneiras. O quarto é menor que o dos homens e abriga menos pessoas. O número total é de 46 elementos, sendo apenas duas criminosas, 43 fugidas e uma depositada. Com as mulheres praticam-se as mesmas crueldades físicas reservadas aos escravos homens, provocando cenas de imoralidade e dor.

A Comissão revela que os presos, de ambos os sexos, vivem amontoados, respirando ar pútrido e insalubre, que leva à morte. Recebem por alimentação uma porção de carne, cozida em água com sal, e misturada com farinha, apenas uma vez por dia.

Os membros da vistoria reforçam a urgência de se construir cadeia nova e sugerem algumas reformas imediatas:

" 1 Que se tire a parede que divide a prisão dos homens da das mulheres, e se forme das duas, uma só prisão para os homens.

2 Que fique servindo para prisão das mulheres o quarto que fica em frente da sala onde vive o carcereiro e sua familia.

3 Que a sala do carceiro fique servindo de sala livre.

4 Que no lugar onde existe a cozinha se faça o quarto do carcereiro. 
5 Que a um dos lados da prisão na frente de leste se faça um telheiro para servir de cozinha, e que o terreno dessa frente se mure, não só para terem os presos a quem isso seja licito algum espaço para tomar ar, mas igualmente para se mudar para esse lugar o (ilegivel), onde se prendem os escravos que se castigão, evitando-se deste modo aos pobres presos o trágico espetáculo, que de contínuo se apresenta aos seus olhos.

6 Que os presos além da comida que tem comão mais uma vez ao dia, e que na sua comida a que ora tem se misture alguma verdura.

7 Que não se continue a prática de castigar os escravos tão barbaramente, sendo mais moderados os castigos, e com o instrumento chamado chicote responsabilizandose o carcereiro pelo abuso que nesta parte houver.

8 Que esta Câmara tome as medidas ao seu alcance para serem curados os presos quando se acharem doentes, fora da $\mathrm{Ca}$ deia por não haver um quarto, onde isto possa fazer-se.

9 Que seja absolutamente vedado que possão os senhores de escravos retê-los a seu arbítrio na Cadeia, porque só devem habitar este lugar os criminosos.

10 Que o depositário geral seja absolutamente inibido de fazer depósito na prisão, porque os escravos que a lei confia a sua guarda não devem, sendo inocentes, habitar o lugar do crime, e porque tendo o depositário geral certos emolumentos do que guarda não deve iludir a lei recebendo a paga sem cumprir a obrigação.

11 Finalmente que se acabe com o abuso de se receberem na cadeia os escravos fu- 
gidos por tempo indefinido, o que segundo parece a Comissão se poderá remediar declarando-se pelas folhas públicas a lista dos fugidos que se acharem presos, com a pena de que não procurando por eles seus senhores, em certo, e determinado prazo, se proceder como a bens de ausentes." 10

A Câmara Municipal de Porto Alegre, após o relatório da Comissão, envia um ofício ao Presidente da Província, pedindo permissão para continuar a receber pagamento com a licença de castigo dos escravos. A Câmara diz que necessita da verba para pagar as luzes e outros misteres indispensáveis na $\mathrm{Ca}-$ deia de Justiça, onde se fazem os ditos castigos. Transmite ao Presidente da Província a cópia de documento que autoriza o Juiz de fora a cobrar as licenças dos castigos em benefício da Câmara. $\mathrm{O}$ texto da Portaria de permissão é o seguinte:

"Mando a Excelentissima Junta Governativa deșta Província que o Senhor Doutor Juiz de Fora desta capital dê as licenças para castigos de escravos depois que se the apresentarem bilhetes do escrivão da Câmara desta mesma capital, pelos quàis se verifique estar paga a esportual competente regulada em cento e setenta réis para cada cem açoites.

Palácio do Governo, 15 de março de 1822.

Manuel Maria P. Marques

Membro do Governo Provisório"11

Os pedidos da 19 Comissão de 1831 não têm o efeito esperado e a condição dos presos brancos e negros continua a mesma.

4 - RELATÓRIO DA SEGUNDA COMISSÃO ENCARREGADA PELA CÂMARA MUNICIPAL DE VISTORIA EM CARCERES E ESTABELECIMENTOSS DE CARIDADE EM PORTO ALEGRE — DEZEMBRO DE 1831

Em dezembro de 1831 nova Comissão é designada para inspecionar as prisões, apresentando também um relatório.

O primeiro presídio visitado pelo grupo é a presiganga. A Comissão explica que o lugar é seguro, porém extremamente 
pequeno para abrigar o número de pessoas que o habita. Acrescenta ainda que, nos dias de trabalho, os prisioneiros, empregados no serviço público, respiram ar puro. Entretanto, nos dias de descanso, quase sufocam com o ar pernicioso do ambiente12.

A alimentação é escassa. Está previsto que cada preso receba $1 \mathrm{lb}$ de carne por dia, porém isto não acontece. Em geral é servido um caldo, onde existe apenas ossos e nada de mais consistente. Os presos vestem-se com roupas doadas por particulares e apenas suficientes para cobrir "aquelas partes do corpo, que a decência exige cobertas". Em tais condições e trabalhando sob sol e chuva, não surpreende que seja alto o indice de mortalidade entre eles.

A Comissão torna-se ainda mais crítica ao referir-se à Cadeia de Justiça. Revela que a Cadeia serve para o desafogo da vingança e da injustiça, caracterizando-se pelo desleixo, desumanidade e desmoralização.

A Comissão descreve os mesmos quadros de horror revelados anteriormente e julga-se inclusive descrente da validade de seu trabalho no momento. Não alimenta esperanças de que suas criticas conduzam a modificações, pois a Comissão anterior já alertou para todos os problemas e nada foi levado em consideração.

A Comissão revela que 38 desgraçados estão encerrados em um só quarto, que tem condições de abrigar apenas a metade deles.

As informações sobre alimentação, poluição do ar e andrajos dos presos coincidem com as informações anteriores. O fornecimento de água para beber é o único dado novo. A Comissão $\mathrm{d}$ 'z que o líquido fica depositado em uma grande pipa, exposta aos calores do sol. A ingestão da água pode causar inúmeras moléstias.

Observa-se que a cadeia abriga, além dos criminosos, em divida com a justiça, individuos que não têm motivos reais de aí permanecerem. A Comissão tem conhecimento de vários abusos nesse sentido, enumerando os seguintes:

" 1 Um escravo de José Gomes da Vila de Cachoeira que tendo se livrado do crime há três meses, ainda se acha preso só 
O Escravo Negro...

porque o seu senhor ausente ainda não satifez certas propinas ao Carcereiro, que de dia em dia aumenta as contas de suas despesas em comedorias que diz que ministra por 60 rs diários, e que não passa de um pedaço de xarque sem mistura alguma mais.

2 Um escravo de José Pereira Maciel, morador em S. Leopoldo ali conservado só porque seu senhor pleiteia com outro sobre a posse do dito escravo.

3 Um preso remetido da Vila do Rio Pardo e ali conservado a ordem da Ouvidor da Comarca, que diz ainda que o mesmo não ter sido interrogado, apesar do espaço de tempo, que tem mediado depois de sua prisão, talvez porque a sua indigência motive o não ter quem promova o seu livramento, sendo no entretanto vítima de alguma vingança - e de alguns outros que ali estando presos a mais de outro ano já deveriam ter obtido despacho. (...) sobre o que a Comissão entende, que é necessário recomendar, que os presos mais antigos sejam os primeiros a obter suas sentenças para assim não sofrerem o prejuizo das delongas e poder a Cadeia melhor acomodar os que estão nas circunstâncias de ali e que por pouca comodidade das tarimbas se vem na dura necessidade de dormirem sobre a fria lage." 13

A Comissão após observar a presença de 13 escravas, entre as mulheres presas, concorda com o parecer da Comissão anterior, condenando a prática de misturar inocência com crime. Sem ilusões sobre a força de suas denúncias para melhorar a situação das cadeias, a Comissão omite deliberadamente detalhes e encerra o relatório sobre a Cadeia de Justiça.

A mesma Comissão ainda visita a Prisão Militar, explicando que se encontra dividida em duas partes. A primeira é para presos puramente militares e a segunda contém 14 presos, mandados pela Cadeia de Justiça, que não tem lugar para eles. 
O relatório informa que os indivíduos são relativamente bem tratados na Prisão Militar. Recebem vestuário e sustento mais fartos e o próprio ambiente físico é melhor arranjado, salubre e decente.

Todavia, no recinto da Cadeia de Justiça reina o desleixo. O vaso destinado para a água não passa de uma tina "imunda e imprópria, a latrina mal asseada e a grade de ferro há oito dias arrombada, ainda sem conserto."'14

A semelhança dos que vivem na Cadeia de Justiça muitos indivíduos da Prisão Militar não sabem porque são mantidos prisioneiros. Salienta-se o caso de um homem, remetido pelo Juiz de Paz da Freguesia de Nossa Senhora dos Anjos, há poucos meses, e que não sabe nada sobre o andamento de seu processo15.

João Batista de Souza Cabral, Bernardo José Rodrigues F., Francisco Vieira de Aguiar, José Pereira de Barros e Antonio Alvares Pereira, assinam o relatório e pedem aos membros da Câmara que não tornem infrutífero o seu trabalho, providenciando imediatamente a melhoria das condições das Cadeias da Capital.

O relatório da Comissão, entregue a 20 de dezembro, é do:s dias depois enviado, pela câmara, ao Presidente da Província - Manuel Antonio Galvão.

O ofício esclarece que as solicitações da primeira Comissão, no que respeita as reformas da casa, que serve de Cadeia Civil, já estão sendo providenciadas.

Finalmente, a 27 de junho de 1835, o Presidente Antonio Rodrigues Fernandes Fraga sanciona o decreto $n \div 2$ da Assembléia Legislativa Provincial, estabelecendo que se crie uma Casa de Correção em cada um dos municípios de Porto Alegre e nas vilas de São Francisco de Paula e Pelotas. As prisões devem situar-se preferencialmente às margens de rios navegáveis e de águas potáveis 16 .

A Revolução Farroupilha desvia a atenção do Governo Provincial e o projeto fica esquecido.

Em 1851, o Vice-Presidente da Província, em exercicio, Luiz Alves de Oliveira Belo, sanciona a Lei de n० 234 que determina verbas e ordens para a construção da Casa de Cor- 
reção da Capital. Três anos depois é concluída a 1ạ seção da cadeia. Em 1855 cerca de 195 presos, que se encontravam provisoriamente nas prisões do $13^{\circ}$ batalhão, são transferidos para as novas instalações.

\section{CONCLUSÃO}

Observa-se que no decorrer do século XIX as condições materiais das prisões porto-alegrenses são péssimas. $O$ sistema dos presídios é falho por dois motivos. Por um lado, não corrige os criminosos e de outro oferece, aos presos, lições diárias de criminalidade e violência.

As condições do escravo são piores do que as vivenciadas pelo prisioneiro branco. A duração do encarceramento do escravo, e o tratamento que recebe, depende da quantia em dinheiro que o senhor pagar aos serviços públicos. Muitas vezes o escravo é preso pelo simples arbítrio do senhor, sem ter culpas contra a sociedade, para expiar.

O decreto no 67 - da Justiça - no período de Feijó determina que nenhum escravo seja condenado ao calabouço, às ordens de seu senhor, por mais de um mês. $\mathrm{O}$ decreto quer evitar os abusos cometidos e prevê que os escravos, nestas condições, sejam expulsos das prisões 17 .

Não se conhece os resultados da aplicação das medidas governamentais contra o autoritarismo dos senhores de escravos e sobre a melhoria das condições dos presídios em Porto Alegre.

Novas pesquisas, no futuro, podem esclarecer tais fatos, determinando o grau de arbitrariedade e força presente na sociedade escravista gaúcha.

Pontificia Universidade Católica do Rio Grande do Sul Departamento de História Porto Alegre - Brasil

NOTAS

1 SAINT HILLAIRE, A. Viagem ao Rio Grande do Sul. São Paulo, Ed. da Universidade de Säo Paulo, 1974. p.

DREYS, Nicolau. Notícia descritiva da Província do Rỉo Grande de Săo Pedro do Sul. J. Villeneuve e Comp., Rio de Janeiro, 1839.

2 COPSTEIN, Raphael. Subsidio do estudo da escravatura no sul do Estado. In: Boletim Gaúcho de Geografia, Associação dos Geógrafos Brasileiros ni 6 julho 1977. 
3 SILVEIRA DE OLIVEIRA, C. \& LUZ DE RIBEIRO, L. C. Evolução urbana de Porto Alegre. Mapa. Arquivo Histórico do Rio Grande do Sul.

4 FERNANDES PINHEIRO. Correspondência. In: Boletim Municipal, n 4 - janeiro/abril de 1940 , p. 71.

5 FERNANDES, H. Org. Constituiçōes do Brasil. Ed. Saraiva, São Paulo. 1967. p. 42.

6 FERNANDES PINHEIRO, Op. cit. Nota 4, p. 72.

7 FERNANDES, H. Op. cit. Nota 5, p. 56.

8 RELATORIO da Comissão encarregada pela Câmara Municipal da vistoria em prisões e estabelecimentos de caridade em Porto Alegre - 3 outubro de 1831. Correspondência da Câmara Municipal de Porto Alegre. Arquivo Histórico do Rio Grande do Sul (material manuscrito).

9 Ibidem.

10 Ibidem.

11 Licença para castigos a escravos. Correspondência da Câmara Muninicipal de Porto Alegre. Arquivo Histórico do Rio Grande do Sul manuscrito).

12 RELATÓRIO da Comissāo encarregada pela Câmara Municipal de vistoria em prisōes e estabelecimentos de caridade em Porto Alegre - Dezembro de 1831. Arquivo Histórico do Rio Grande do Sul (material manuscrito).

13 Ibidem.

14 Ibidem.

15 O Decreto $n \div 4$ - da Justiça - de 2/1/32 determina o andamento dos processos judiciários das pessoas miseráveis, procurando evitar que os individuos fiquem esquecidos nas cadeias ou porque são pobres ou porque não são bem relacionados. No momento da visita desta Comissão às prisōes de Porto Alegre verificam-se muitos abusos neste sentido. In: Colleção de Leis do Império, p. 3.

16 KRAEMER NETO. A casa de correção que vai desaparecer. Porto Alegre, Correio do Povo, 1967.

17 Decreto n 67 - da Justiça - 1832. In: Colleção das Leis do Império.

18 Decreto $n$ 18 - Fazenda - 28/1/28. Declara que o destino que devem ter os escravos metidos em prisōes e depósitos quando abandonados por seus donos. Decreto que visa terminar com os abusos dos senhores que transformam as instituições públicas em depósitos para os escravos. 


\section{REFERENCIAS BIBLIOGRAFICAS}

1 CORRESPONDENCIA da Câmara Municipal de Porto Alegre - 18301832. Arquivo Histórico do Rio Grande do Sul. Material manuscrito (Coleção).

2 SCHWARTZ, S. Burocracia e sociedade no Brasil. São Paulo E. Perspectiva, 1979.

3 MALHEIRO, Perdigão. A escravidão no Brasil. Ensaio histórico, jurídico, social. Petrópolis, Vozes, 1976.

4 FENELON, Léa. Levantamento e sistematização da legislação relativa aos escravos do Brasil. Separata dos Anais do VI Simpósio Nacional dos Professores Universitários de História. V. II. São Paulo, 1973.

5 BAKOS, M. RS: Escravismo e abolição. Porto Alegre, Mercado Aberto. 1982. 